\title{
Medicine and Music
}

\section{Looking for Mozart ears}

\author{
ALEX PATON, AHMES L PAHOR, GERALD R GRAHAM
}

\begin{abstract}
It is a peculiar irony of fate that the man whose inner ear has, so to speak, the highest human development has a retarded and malformed outer ear.
\end{abstract}

GERBER, 1898

Our quest for Wolfgang Amadeus Mozart (1756-91) in the realms of otology was prompted by the case of a young girl with several developmental abnormalities which included curiously flat and rounded ears. These were called Mozart ears, but reference to currently available textbooks on diseases of the ear yielded only scanty descriptions, and a straw poll among colleagues in other disciplines disclosed no one who knew what they were or why they were so called. The questions we asked were: "What exactly are Mozart ears?" "How common are they?" and "How have they come by such a distinguished eponym?" After three years of intermittent investigation our findings are still incomplete, but they may encourage others to provide solutions to an intriguing puzzle.

\section{What are Mozart ears?}

The aesthetic beauty of the human ear depends on its oval, shell like shape, bounded on the outside by a clearly differentiated helix and at the bottom by a more or less developed ear lobe (fig 1). The area called the antihelix between helix and external auditory meatus is normally buried in the general concavity of the pinna.

By contrast Mozart ear has a round and sometimes almost square appearance (fig 2). The prominent antihelix tends to jut out and obliterate the curve of the helix; in some cases this is so great that the upper half of the ear is flat and there is virtually no helical curve. The ear lobe is ill developed or absent. One or both ears may be affected.

In order to familiarise ourselves with variations in the appearance of the ear we examined a collection of 888 photographs of facial profiles from patients who had been about to undergo plastic operations. We found 13 examples of Mozart ear-they were not difficult to spot-and this experience was used to determine the prevalence of the condition in the population.

We carried out two surveys, the first involving 1185 consecutive patients attending an ear, nose, and throat clinic in Birmingham and the second of 1092 patients in two medical clinics in London. In each case only one patient with Mozart ear was found- an elderly man with carcinoma of the larynx and a man in his 50 s with chronic bronchitis; both were white. The patients came from a great variety of ethnic backgrounds, and there were not enough in each category to make statements about prevalence in different races. But the general prevalence in a hospital population seems to be less than one in a 1000 .

\section{Why Mozart?}

A note in La Chronique Médicale records that in the room in Salzburg where Mozart was born there is
"a strange watercolour which shows two ears: one is the ear of the author of Don fuan, the other the ear of a common mortal .... The edge of the ear, instead of being rounded as it is normally is an interrupted curve, abruptly folded at an obtuse angle, the pinna which usually takes the form of a shell, presents a flat surface and is hardly shaped; the fleshy part shows the same anomalies as the cartilage and the lower lobe has a complete defect. Together with that, the entire ear is of unusual size, and instead of being elongated as has generally evolved in superior races, for example in Caucasians, is distinguished by greater width normally attributed to less civilised races."

On a recent visit to Salzburg we were unable to find the watercolour in Mozart's birthplace (now a museum) at 9 Getreidegasse. 
The director of the Mozarteum;Dr Rudolph Angermüller, kindly sent a photocopy of the ears from an illustration in the biography of the composer written in 1828 by $\mathrm{G} \mathrm{N}$ von Nissen, the husband of Mozart's widow, Constanze. ${ }^{2}$ The illustration, "Mozart's left ear"

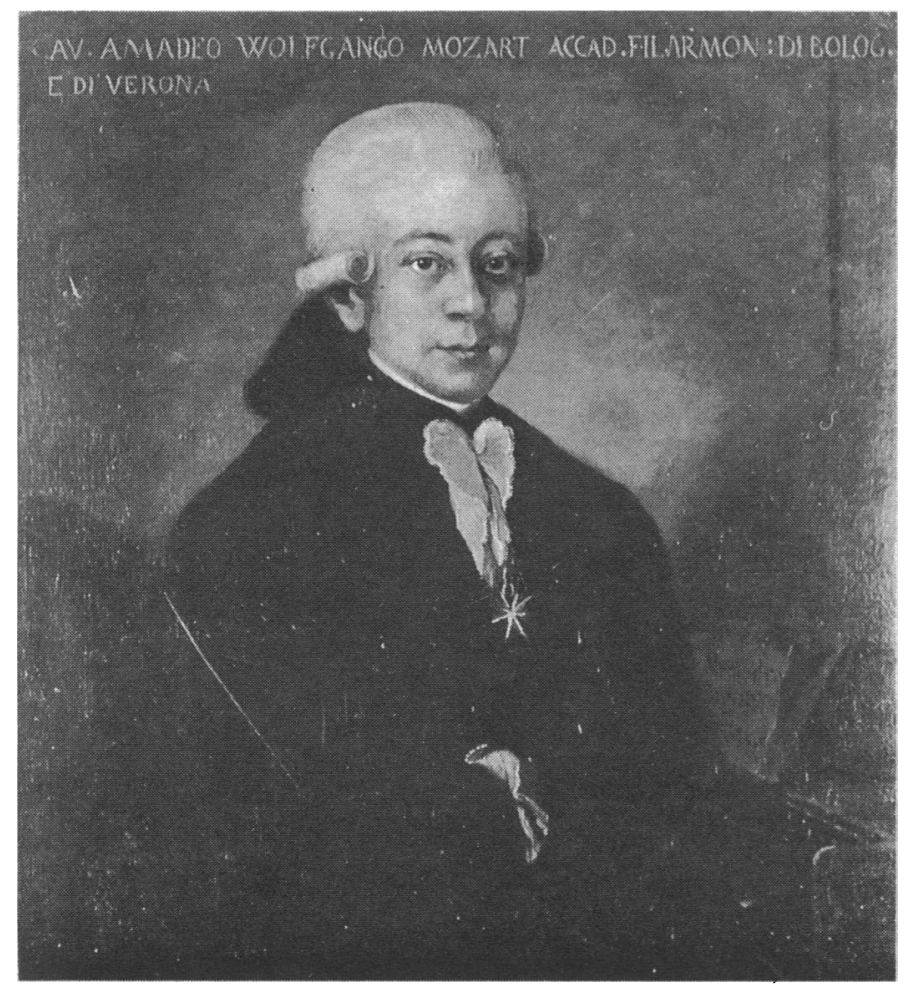

Mozart as Knight of the Golden Spur 1777. Photograph supplied by the Internationale Stiftung Mozarteum, Salzburg, Austria.

together with a normal ear for comparison, appears near the end of the massive biography, and accompanies a short comment on the composer's younger son, Franz Xavier (who later took the name Wolfgang Amadeus Junior): "The facial features and ears of the son Wolfgang are similar to those of his father. What seems to be extraordinarily peculiar is the structure of Mozart's ear, quite

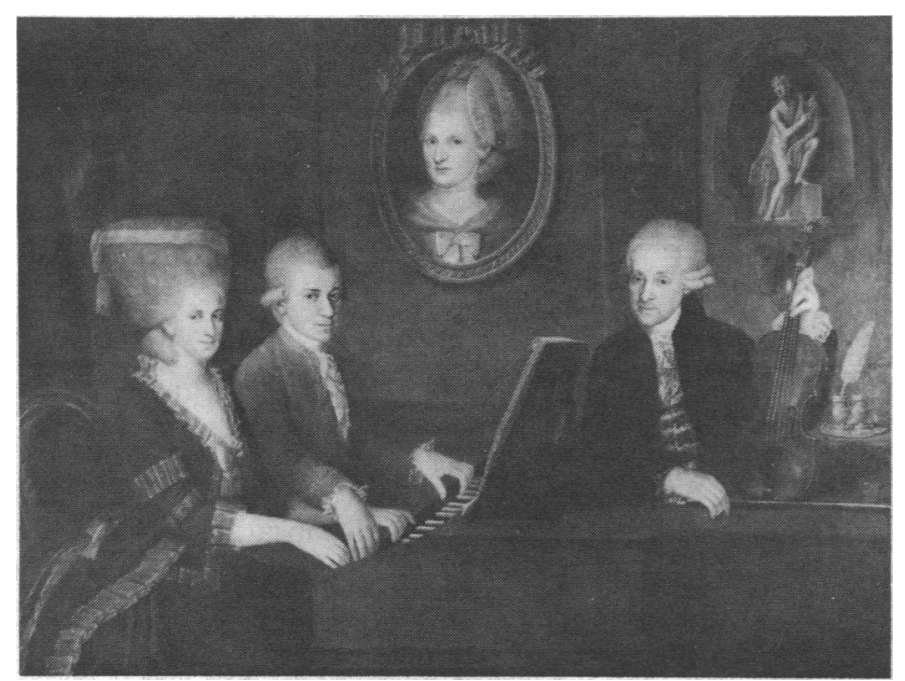

The Mozart family by Johann Nepomuk 1780. Photograph supplied by the Internationale Stiftung Mozarteum, Salzburg, Austria different from the normal, and which to mention en passant, was inherited from him only by his youngest (sic) son. It can be seen from the attached illustration wherein lies the difference." Since the biography was written with the assistance of Constanze it is reasonable to assume that she accepted these descriptions.

Gerber, in discussing the ears, says that there was no illustration in the copy of the biography available to him, and so he had to draw one from the watercolour. ${ }^{3}$ This shows well the angularity and absence of the lobe, but it differs from Nissen's illustration in possessing an earring. In a more extended anatomical investigation Holl points out that it is wrong to assume, as Nissen did, that both ears were affected. ${ }^{4}$ Indeed, three oil paintings of Mozart, of which the clearest is the anonymous Mozart as a Knight of the Golden Spur (1777), currently on exhibition at his birthplace, show normal

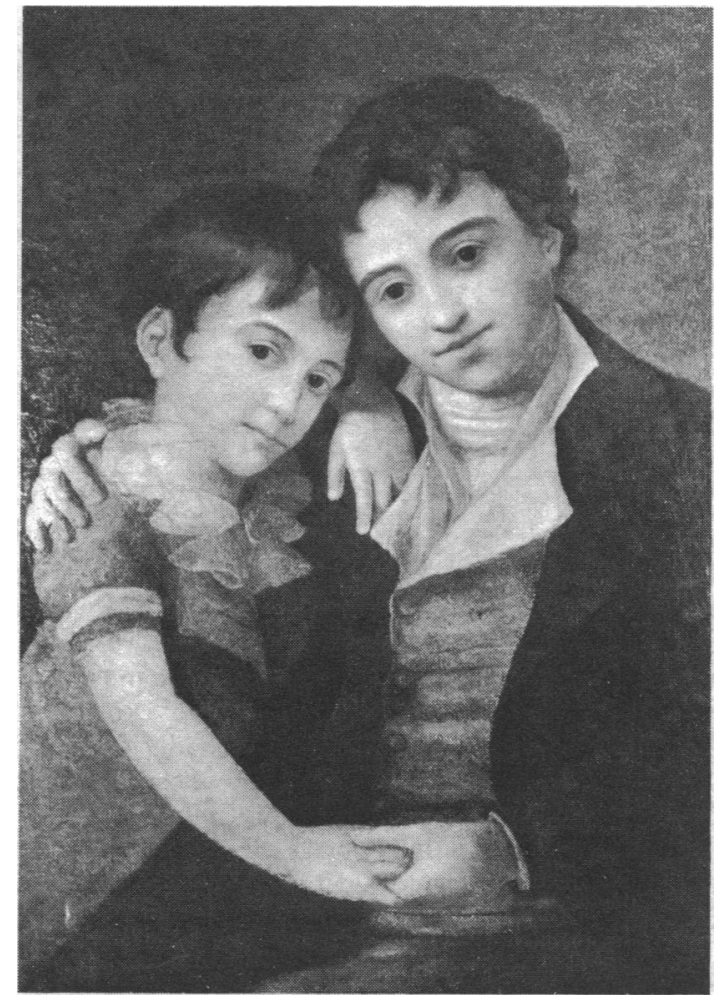

Carl and Wolfgang Amadeus Junior, Mozart's two sons, by Hans Hansen c1798. Photograph supplied by the Internationale Stiftung Mozarteum, Salzburg, Austria.

right ears (fig 3). The lower half of the right ear in the well known Family Portrait by Johann Nepomuk della Croce (1780) might be considered abnormally "square" when compared with that of his sister, Nannerl, but its appearance suggests that artistic licence is more likely (fig 4).

It is more difficult to give a definite opinion about the left ear, not only because almost all portraits show Mozart's right profile but because the sole available evidence that we have seen is an early miniature of 1773 attributed to Martin Knoller, which shows a very odd looking child's face and a peculiarly drawn left ear, in appearance quite unlike Mozart ear. The right ear of Mozart's younger son is normal in the portrait of the two sons by Hans Hansen (fig 5), and the only painting in the museum of his left profile, by Karl Schweikart (1825), shows part of a normal left ear. But an anonymous oil of about 1840 of Carl, the elder son, has a mere blob for the left ear, illustrating once again the difficulty of excluding artistic interpretation.

There is a further mystery. Gerber says that he copied the watercolour rather than Nissen's lithograph, but a reproduction of 
the watercolour in Holl's paper not only has the earring but also an indistinct word between "Mozart's" and "Ohr." He says that this refers to the younger son and that the attribution to Mozart was a mistake of Nissen's. It would be interesting to know the present whereabouts of the watercolour so that it could be studied in more detail. In the meantime we are forced to the conclusion that there is no portrait showing the left ear of the composer himself.

A final question remains. Who first gave this striking but rare abnormality its present eponym? It may be that the practice resulted from Gerber's paper being published in a widely read clinical journal. Justification for the label, however, seems to be scant, and the attribution in the quotation at the beginning of this account may need to be refuted as strongly as the suggestion that the anomaly represents a primitive throwback.

We should like to thank Jean McCulloch of Dudley Road Hospital, Birmingham, for putting the expertise of her photographic department at our disposal.

\section{References}

1 Anonymous. L'oreille de Mozart. La chronique médicale 1898;5:576.

2 von Nissen GN. Biographie W A Mozart's. Herausgegeben von Constanze, Wittwe von Nissen, früher Wittwe Mozart. Leipzig; Breitkopf and Hartel, 1828.

Wittwe Mozart. Leipzig; Breitkopf and Hartel, 1828.
Gerber PH. Mozart's ohr. Dtsch Med Wochenschr 1898;24:351-2.

4 Holl M. Mozart's ohr. Mitt Anthropol Gesellschaft (Wien) 1901;21:1-12.

British Postgraduate Medical Federation, London WCIN 3EJ

ALEX PATON, MD, FRCP, regional postgraduate dean

Ear, Nose, and Throat Department, Dudley Road Hospital, Birmingham B18 7QH and Sandwell District General Hospital, Birmingham

AHMES L PAHOR, MB, FRCs, consultant surgeon

Hospital for Sick Children, London WC1N 3JH

GERALD R GRAHAM, BA, MD, consulting clinical physiologist

Correspondence to: Dr Paton, British Postgraduate Medical Federation, 33 Millman Street, London WC1N 3EJ.

\section{Rachmaninov and Marfan's syndrome}

\section{A B YOUNG}

Large hands may not be essential for virtuoso pianists-witness Hofmann and Moiseiwitsch-but they must surely be advantageous when playing works by Sergei Rachmaninov (1873-1943). The distinguished pianist Cyril Smith thought his own hands were large, each being capable of spanning a twelfth; but Rachmaninov's hands, long and tapering, were the largest he had ever seen, with a stretch so wide that they "covered the keyboard like octopus tentacles." When it came to playing Smith says that he could achieve Rachmaninov's feat of playing as a chord C, E $, \mathrm{G}, \mathrm{C}$, and G with the left hand but was defeated by his Russian friend's right hand stretch on the chord C (2nd finger), E, G, C, and E (thumb under). Smith comments: "This was a scarcely credible performance, which was probably unique."

This unusual fingering of the $\mathrm{C}$ major chord requires much more than simply a giant hand. To be able to stretch the thumb under the hand to that extent (nine inches) an extraordinary degree of extensibility is required. A possible explanation is as follows. If, in withdrawing his hand from the keyboard after playing that chord and without altering the disposition of the thumb relative to the fingers, Rachmaninov had clenched his hand the opposed thumb would have extended well beyond the ulna border of the hand. This would have constituted a classic example of the thumb sign indicating Marfan's syndrome. ${ }^{2}$

\section{Marfan's syndrome}

Marfan's syndrome is a hereditary disarrangement of connective tissue affecting one or more of three systems: skeletal, visual, and cardiovascular. ${ }^{3}$ Of the skeletal features, the most characteristic are

\section{Downham Market, Norfolk PE38 9ND}

D A B YOUNG, MA, MPHIL, formerly principal scientist, Wellcome Foundation

Correspondence to: Dr D A B Young, 23 Hillcrest, Downham Market, Norfolk PE38 9ND.

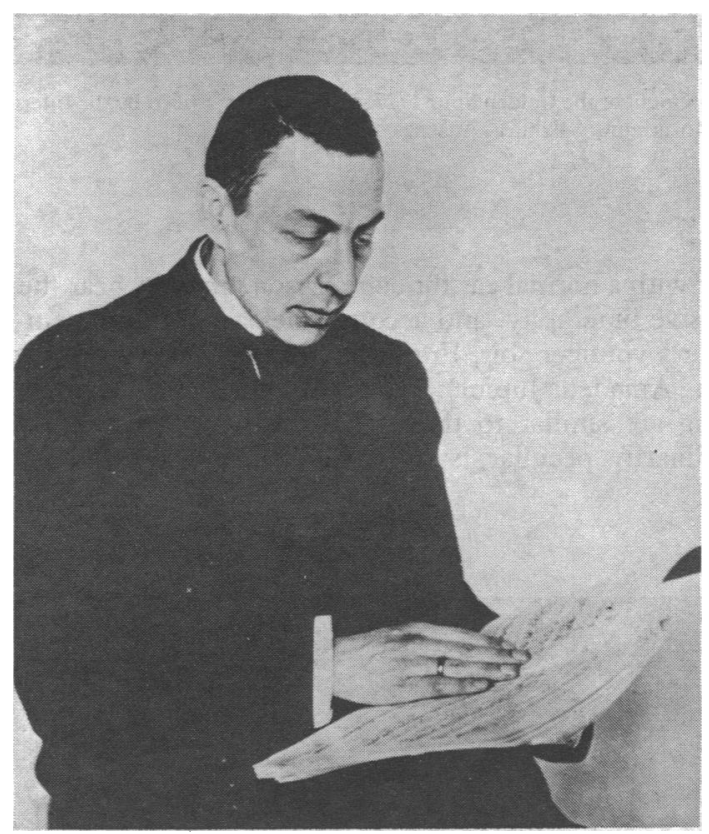

Sergei Rachmaninov (1913).

the excessive growth of long bones, leading to greater than normal stature and to limbs disproportionately long compared with the trunk, and disproportionately long and slender fingers and toes (arachnodactyly). The head is often narrow (dolichocephalic) with long facial features. A striking sparcity of subcutaneous fat exaggerates the already linear structure. Other skeletal abnormalities that may occur are overgrowth of the ribs, leading to anterior chest deformity, and weakness and laxness of ligaments, tendons, and fasciae that may produce kyphoscoliosis, pes plana, loose jointedness, and malpositioned ears. In the visual system dislocation of the lenses is diagnostic of the condition; myopia due to increased 